\title{
ERRATUM
}

\section{Erratum to: Various Regulatory Modes for Circadian Rhythmicity and Sexual Dimorphism in the Non-Neuronal Cardiac Cholinergic System}

\author{
Shino Oikawa ${ }^{1} \cdot{\text { Yuko } \mathrm{Kai}^{1} \text { - Asuka Mano }}^{1} \cdot$ Hisayuki Ohata $^{1} \cdot$ Takahiro Nemoto $^{1}$. $^{1}$ \\ Yoshihiko Kakinuma ${ }^{1}$
}

Published online: 22 June 2017

(C) Springer Science+Business Media, LLC 2017

Erratum to: J. of Cardiovasc. Trans. Res., pp. 1-12

DOI 10.1007/s12265-017-9750-4

Please note that in Fig. 4b, and in the caption for Fig. 4b, the word "Cardiac" should be deleted. A correct version of the figure and caption for it are presented below.
The online version of the original article can be found at http://dx.doi.org/ $10.1007 / \mathrm{s} 12265-017-9750-4$

Yoshihiko Kakinuma

k12417853@nms.ac.jp

1 Department of Physiology, Nippon Medical School Graduate School of Medicine, Tokyo, Japan b

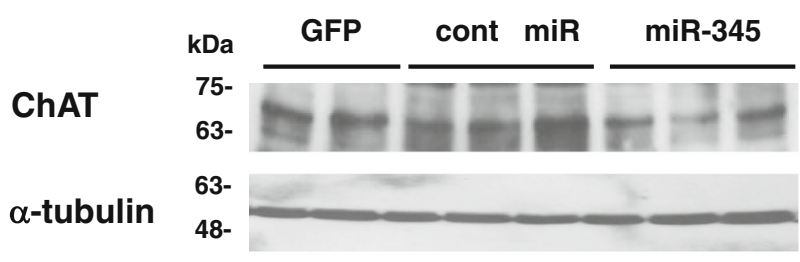

SV skin fibroblasts

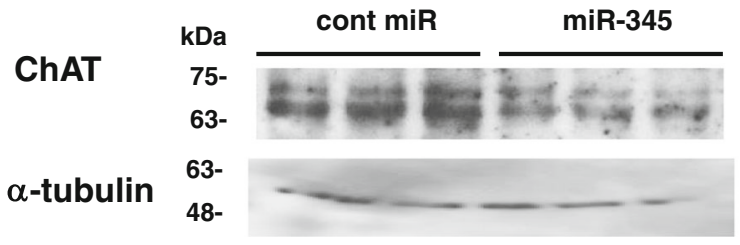

ACh contents



Fig. 4 (b) Western blots showing that miR-345 overexpression attenuated ChAT protein expression in both Neuro-2a and SV cells in comparison with GFP overexpression. ACh contents were significantly decreased by miR-345 overexpression $(P<0.05)$ 